\title{
Information Content of DSGE Forecasts
}

\author{
Ray C. Fair* \\ August 2018
}

\begin{abstract}
This paper examines the question whether information is contained in forecasts from DSGE models beyond that contained in lagged values, which are extensively used in the models. Four sets of forecasts are examined. The results are encouraging for DSGE forecasts of real GDP. The results suggest that there is information in the DSGE forecasts not contained in forecasts based only on lagged values and that there is no information in the laggedvalue forecasts not contained in the DSGE forecasts. The opposite is true for forecasts of the GDP deflator.
\end{abstract}

\section{Introduction}

This paper examines the question whether information is contained in forecasts from DSGE models beyond that contained in lagged values. Lagged variables enter DSGE models through assumptions like habit formation, adjustment costs, variable capacity utilization, pricing behavior, and interest rate rules. Theoretical

\footnotetext{
${ }^{*}$ Cowles Foundation, Department of Economics, Yale University, New Haven, CT 065208281. Phone: 203-980-0646; e-mail: ray.fair@yale.edu; website: fairmodel.econ.yale.edu. I am indebted to Rochelle Edge, Refet Gürkaynak, Marcin Kolasa, Michal Rubaszek, Pawel Skrzypczyński, Maik Wolters, Michael Cai, Marco Del Negro, Marc Giannoni, Abhi Gupta, Pearl $\mathrm{Li}$, and Erica Moszkowski for supplying me with their forecast data. I am also indebted to David Childers for helpful comments.
} 
restrictions are imposed on these variables, and the question is whether predictive information is added by the restrictions?

Consider an $s$-period-ahead forecast of real GDP. Let $Y_{t}^{a}$ denote the $s$-period ahead forecast of $\log$ GDP for period $t$ from model $a$, and let $Y_{t}^{b}$ denote the same from model $b$. The forecasts are assumed to be made at the end of period $t-s$. The comparison method used in this paper is discussed in Fair and Shiller (FS) (1990). For the $s$-period-ahead forecasts for periods 1 through $T$, the following regression is run:

$$
Y_{t}-Y_{t-s}=\alpha+\beta\left(Y_{t}^{a}-Y_{t-s}\right)+\gamma\left(Y_{t}^{b}-Y_{t-s}\right)+u_{t}, \quad t=1, \ldots, T
$$

If neither model contains information useful for $s$-period-ahead forecasting of $Y_{t}$, then the estimates of $\beta$ and $\gamma$ should both be zero. In this case the estimate of the constant term $\alpha$ would be the average $s$-period-change in $Y$. If both models contain independent information for $s$-period-ahead forecasting, then $\beta$ and $\gamma$ should both be nonzero. If both models contain information, but the information in, say, model $b$ is completely contained in model $a$ and model $a$ contains further relevant information as well, then $\beta$ but not $\alpha$ should be nonzero. (If both models contain the same information, then the forecasts are perfectly correlated, and $\beta$ and $\alpha$ are not separately identified.) It may be that both coefficient estimates are significant, but one is negative. This means that the information contained in the forecast of the model with the negative coefficient estimate contributes negatively to the overall forecast conditional on the information in the other model's forecast.

One model's forecasts may have a higher root mean squared error (RMSE) than another's, but still contain useful independent information. Estimating equation 
(1) allows one to test for this, which the simple comparison of RMSEs cannot.

Further discussion of this method is in Fair and Shiller (1990). The error term $u_{t}$ is likely to be heteroskedastic and be a $s-1$ moving average process. This can be corrected for when estimating the standard errors of the coefficient estimates. The procedure discussed in Hansen (1982), Cumby, and Obstfeld (1983), and White and Domowitz (1984) can be used to estimate the asymptotic covariance matrix of the coefficient estimates. When $s$ equals 1 the covariance matrix is simply White's (1980) correction for heteroskedasticity.

In the next section a set of comparison rules is suggested. The forecasts are discussed in Section 3, and comparison results are presented in Section 4.

\section{Suggested Comparison Rules}

1. Use a common forecast period. Some periods are obviously more difficult to forecast than others, and so a common period is essential.

2. With the exception discussed in point 3 , no future information should be used in making the forecasts. Rolling estimation can be used up to the first period forecast, so no future information is in the coefficient estimates. If there are exogenous variables, no future information should be used to forecast these variables. Possibilities are mechanical rules or autoregressive equations. In principle future information should not be used in calibrating parameters, although this may be hard to do. Future information may also have been used in the specification the model, since the latest specification is likely to 
be used. This then means that the forecasts are not true ex ante forecasts. The comparison exercise is conditional on the theoretical specification of the model and possibly on some calibrated parameters.

3. Use the latest revised data for the comparisons. The latest revised data may also be used for the estimation, which is where future information comes in. The latest revised data are the best estimates of the economy, which argues for their use. Also, even if real time data are used in the estimation, it is not clear what data should be used for the future comparisons. Using, say, the first or second estimate of the future data seems worse than using the latest data, since one is after the best estimate of the economy. Fortunately, as discussed below, using real time versus latest revised data generally makes only a small difference in the results.

4. The forecasts should be made by the proprietors of the models. Models are complicated, and proprietors know them best. Allowing an outsider to generate the forecasts increases the chances of errors and of misrepresenting the model. One, of course, has to trust that the proprietors are not cheating, but programs can be made available to others to duplicate the results.

\section{The Forecasts}

\section{DSGE Forecasts}

Four sets of forecasts from DSGE models were used: Wolters (2013), Kolasa, Rubaszek, and Skrzypczyński (KRS) (2012), Edge and Gürkaynak (EG) (2010), 
and Cai, Del Negro, Giannoni, Abhi, Li, and Moszkowski (NYFRB) (2018). The forecast periods differ, but the forecasts have all been generated using no future information except for the specification of the model, possibly some calibrated parameters, and possibly the use of revised data. Also, for the NYFRB forecasts the Blue Chip expectations of the future federal funds rate and the ten-year inflation rate are taken as "data" during the zero lower bound period.

Forecasts of real GDP and the GDP deflator have been used from the four studies. In addition forecasts of consumption and investment have been used for NYFRB. The earliest forecast period is Wolters, 1984:1-2002:4. Wolters compares four models, and I have taken the Smet-Wouters model for the present analysis. Wolters uses both real-time data and revised data for the estimation, and in the spirit of the suggested rules in Section 2, I have taken the version using revised data. Wolters reports (p. 87) that the relative performance of the models is not sensitive to which data are used. I have also used the forecasts with jump off date -1 . There are 5 missing forecasts in the data set, so the total number of observations is 63 . This forecast period does not include the housing boom of the early 2000's nor the recession that followed. Forecasts are available for up to 9 quarters ahead.

For KRS the forecast period is 1994:1-2008:4. This includes the housing boom period, but only the first few quarters of the recession. There are 56 observations. Forecasts are available for up to 5 quarters ahead. KRS use real-time data for the estimation of the model, but revised data for the forecast evaluations - the last vintage data in their sample. They report (p. 1313) that results using other "actuals" are broadly the same. The model is essentially the Smets-Wouters model.

For EG the forecast period is 1992:1-2010:1, so it does include the recession. 
EG analyze two forecast periods, and this is the longer of the two. They use realtime data for the estimation. For the longer period used here the vintage dates are Blue Chip dates. Forecasts up to 8 quarters ahead are available, but the data are such that there is one fewer observation per quarter ahead. There are 73 observations for the 1-quarter-ahead forecast, 72 for the 2-quarter-ahead, through 66 for the 8-quarter-ahead.

For NYFRB there are 97 16-quarter-ahead forecasts, with start dates 1992:1 through 2006:1. Real-time data are used for the estimation, and the model is reestimated once a year. The forecasts are from model SWFF, which is the Smets and Wouters (2007) model augmented with financial frictions.

The data I have used for the comparisons are revised data as of January 26, 2018, which have observations through 2017:4. This means for the NYFRB forecasts that errors are available for all 97 8-quarter-ahead forecasts and earler. For the 9-quarter-ahead forecasts 96 errors are available, and so on through the 16-quarterahead forecasts, where 89 errors are available. . The forecasts are available from the model builders as quarterly percentage changes. I have converted these forecasts to level forecasts using for each variable the actual value (from the revised data) on the level of the variable for the quarter before the first quarter forecast. Computing level forecasts allows one to compare $s$-period-ahead forecasts for $s$ greater than one.

So to summarize, I have taken the exact percentage change forecasts from the model builders - one set based on estimates using revised data (Wolters) and the other three on real-time data — converted these to levels using the latest revised data for initial starting points, and used the latest revised data for the forecast-period 
comparisons.

\section{Forecasts using only Lagged Variables}

The model used to generate the forecasts of the GDP deflator will be denoted PAR4. This model is a single linear equation, where the left hand side variable is the log of the GDP deflator and the right hand side variables are the constant term and the first four lagged values of the log of the GDP deflator-a fourth-order autoregressive equation. 172 sets of forecasts were generated. The beginning quarter for all the estimations was 1954:1. The data ended in 2017:4. For the first set the end estimation quarter was 1974:4, and the forecast period was 1975:1 through 1978:4. For the second set the respective quarters were 1975:1 and 1975:2 through 1979:1, and so on. This gave 172 1-quarter-ahead forecasts through 157 16-quarter-ahead forecasts. These sets were matched to the relevant DSGE sets for the comparisons; not all sets were used.

The model for real GDP uses lagged values of the components of real GDP and the GDP identity. It will be denoted YSAR4. Ten components of real GDP were chosen, where real GDP is the sum of the ten. An AR4 equation is specified for each component, where the log of a component is taken to be a linear function of the constant term and the first four lagged values of the log of the component 1 YSAR4 thus consists of 11 equations, the 10 component equations and the GDP identity.

\footnotetext{
${ }^{1}$ The ten components are (all using real NIPA data) consumption of services, consumption of nondurables, consumption of durables, residential investment, fixed nonresidential investment, inventory investment, exports, imports (with a minus sign), government spending (sum of federal and state and local), and a statistical discrepancy term due to the use of chain-linked data. For inventory investment and the statistical discrepancy, logs were not taken for the component's AR4 equation.
} 
The same estimation procedure was followed for YSAR4 as that for PAR4. There are no exogenous variables in the model, and so no future information is used for the forecasts except for the use of the latest revised data.

As noted in Section 1, for the NYFRB forecasts comparisons are also made for consumption and investment. This requires a little more explanation. There are three consumption components in YSAR4: service, nondurable, and durable. Total real consumption is the sum of these three. The model for consumption, denoted CSAR4, is taken to be the three AR4 equations for the components plus the equation summing the three. The total consumption forecasts are then compared to the NYFRB consumption forecasts described above. Remember that the NYFRB level consumption forecasts are generated using the actual value of total real consumption in the quarter before the forecast begins plus the real consumption growth rates from the DSGE model. In most DSGE models, including NYFRB, real consumption is mismeasured. It is taken to be nominal consumption divided by the GDP deflator. The growth rates are thus growth rates of a mismeasured variable, whereas the actual initial value of the level of real consumption that is used to generate the level forecasts is the correct value. Also, the DSGE level forecasts that are generated are compared to the correct actual values of the levels (not the mismeasured levels). In other words, the assumption here is that the NYFRB growth rates of real total consumption are the growth rates of the correct value even though they are of the mismeasured value.

Regarding investment, there are two fixed investment components in YSAR4: nonresidential and residential. Total real fixed investment is the sum of the two. The model for consumption, denoted ISAR4, is taken to be the two AR4 equations 
for the components plus the equation summing the two. The total fixed investment forecasts are then compared to the NYFRB investment forecasts descrbed above. Similar issues pertain to investment as pertained to consumption above. For NYFRB investment is mismeasured as nominal investment divided by the GDP deflator, but this is essentially ignored here.

Finally, for NYFRB one can examine the difference between GDP and consumption plus investment. This difference is inventory investment plus exports minus imports plus government spending plus the statistical discrepancy term. Results are also presented for this difference, denoted OTHER, below. A forecast of OTHER is simply the forecast of real GDP minus the forecasts of consumption and investment.

In the estimation of equation (1) in the next section, the procedure discussed in Section 1 was use for the estimation of the standard errors of the coefficient estimates except for Wolters. For Wolters there are 5 missing observations, and no adjustments were made to the OLS estimates of the standard errors.

\section{The Results}

Estimates of equation (1) for the four sets of forecasts are presented in Table 1 for real GDP. The quarters ahead analyzed are 2, 4, and 9 for Wolters, 2 and 5 for KRS, 2, 4 and 8 for EG, and 2, 4, 8, and 12 for NYFRB.

The results in Table 1 are clear: the DSGE forecasts dominate the YSAR4 forecasts. The estimates of $\beta$ are always significant, and only two of the estimates of $\gamma$ are. The results thus say that the DSGE forecasts of real GDP contain independent 
Table 1

Estimates of Equation (1) for Real GDP

$Y_{t}-Y_{t-s}$ is the left-hand-side variable.

\begin{tabular}{|c|c|c|c|c|c|c|}
\hline$s$ & $\begin{array}{c}\text { cnst } \\
\hat{\alpha}\end{array}$ & $\begin{array}{c}\text { DSGE } \\
\hat{\beta}\end{array}$ & $\begin{array}{c}\text { YSAR4 } \\
\hat{\gamma}\end{array}$ & SE & $\mathrm{R}^{2}$ & \# obs. \\
\hline \multicolumn{7}{|c|}{ Wolters: 1984:1-2002.4 } \\
\hline 2 & $\begin{array}{l}0.009 \\
(2.10)\end{array}$ & $\begin{array}{l}0.332 \\
(2.34)\end{array}$ & $\begin{array}{l}0.338 \\
(0.90)\end{array}$ & 0.0079 & 0.127 & 63 \\
\hline 4 & $\begin{array}{l}0.037 \\
(3.82)\end{array}$ & $\begin{array}{l}0.328 \\
(2.21)\end{array}$ & $\begin{array}{l}-0.484 \\
(-1.17)\end{array}$ & 0.0134 & 0.083 & 63 \\
\hline 9 & $\begin{array}{l}0.144 \\
(6.03)\end{array}$ & $\begin{array}{l}0.293 \\
(2.02)\end{array}$ & $\begin{array}{l}-1.605 \\
(-3.64)\end{array}$ & 0.0213 & 0.212 & 63 \\
\hline \multicolumn{7}{|c|}{ KRS: 1994:1-2008:4 } \\
\hline 2 & $\begin{array}{l}-0.001 \\
(-0.36)\end{array}$ & $\begin{array}{l}0.657 \\
(2.97)\end{array}$ & $\begin{array}{l}0.522 \\
(1.37)\end{array}$ & 0.0066 & 0.307 & 56 \\
\hline 5 & $\begin{array}{l}0.004 \\
(0.29)\end{array}$ & $\begin{array}{l}1.010 \\
(3.31)\end{array}$ & $\begin{array}{l}-0.213 \\
(-0.40)\end{array}$ & 0.0137 & 0.414 & 56 \\
\hline \multicolumn{7}{|c|}{ EG: 1992:1-2010:1 } \\
\hline 2 & $\begin{array}{l}0.709 \\
(2.97)\end{array}$ & $\begin{array}{l}0.518 \\
(3.01)\end{array}$ & $\begin{array}{l}1.102 \\
(2.01)\end{array}$ & 0.0097 & 0.308 & 71 \\
\hline 4 & $\begin{array}{l}1.262 \\
(3.63)\end{array}$ & $\begin{array}{l}0.922 \\
(3.57)\end{array}$ & $\begin{array}{l}0.226 \\
(0.53)\end{array}$ & 0.0172 & 0.275 & 70 \\
\hline 8 & $\begin{array}{l}2.035 \\
(3.51)\end{array}$ & $\begin{array}{l}1.502 \\
(3.36)\end{array}$ & $\begin{array}{l}-0.436 \\
(-0.68)\end{array}$ & 0.0231 & 0.500 & 66 \\
\hline \multicolumn{7}{|c|}{ NYFRB: 1992:1-2016:1 } \\
\hline 2 & $\begin{array}{l}1.552 \\
(6.76)\end{array}$ & $\begin{array}{l}1.122 \\
(6.75)\end{array}$ & $\begin{array}{l}0.379 \\
(1.47)\end{array}$ & 0.0066 & 0.590 & 97 \\
\hline 4 & $\begin{array}{l}1.504 \\
(4.52)\end{array}$ & $\begin{array}{l}1.082 \\
(4.52)\end{array}$ & $\begin{array}{c}-0.038 \\
(0.08)\end{array}$ & 0.0134 & 0.426 & 97 \\
\hline 8 & $\begin{array}{l}1.280 \\
(3.02)\end{array}$ & $\begin{array}{l}0.904 \\
(2.95)\end{array}$ & $\begin{array}{l}-0.298 \\
(-0.53)\end{array}$ & 0.0252 & 0.250 & 97 \\
\hline 12 & $\begin{array}{l}1.313 \\
(1.98)\end{array}$ & $\begin{array}{l}0.935 \\
(1.93)\end{array}$ & $\begin{array}{l}0.026 \\
(0.05)\end{array}$ & 0.0351 & 0.203 & 93 \\
\hline
\end{tabular}

$Y$ is the $\log$ of real GDP.

OLS estimates.

$\mathrm{t}$-statistics are in parentheses. 10

Estimated standard errors are corrected for heteroscedasticity and a moving average process (except for Wolters). 
information from that contained in the lagged values. Also, the YSAR4 forecasts contain no information not contained in the DSGE forecasts.

Although not reported in the table, results were obtained where the YSAR4 forecasts were replaced with forecasts from a simple fourth-order autoregressive process for real GDP. In other words, the components of real GDP were not used. In this case the results for the DSGE forecasts were even better. So the positive results for the DSGE forecasts are not due to something weird about the YSAR4 model.

The results for the price forecasts are in Table 2, which has the same format as Table 1. The alternative model is simply PAR4, a fourth order autoregressive process for the log of the GDP deflator. In this case the DSGE forecasts do not do well. For Wolters and NYFRB the PAR4 forecasts completely dominate. None of the estimates of $\beta$ are significant, and the estimates of $\gamma$ always are. The PAR4 forecasts contain independent information from that contained in the DSGE forecasts, and the DSGE forecasts contain no information not contained in the PAR4 forecasts.

For KRS and EG the estimates of $\beta$ are negative and significant or close to being significant. The estimates of $\gamma$ are significant and close to 1.0. This suggests that conditional on the PAR4 forecasts, the DSGE forecasts contain additional information, where the additional information contributes negatively to the overall forecast of the GDP deflator. In this case both the DSGE and PAR4 forecasts contain independent information. 
Table 2

Estimates of Equation (1) for the GDP Deflator $P_{t}-P_{t-s}$ is the left-hand-side variable.

\begin{tabular}{|c|c|c|c|c|c|c|}
\hline$s$ & $\begin{array}{c}\text { cnst } \\
\hat{\alpha}\end{array}$ & $\begin{array}{c}\text { DSGE } \\
\hat{\beta}\end{array}$ & $\begin{array}{c}\text { PAR4 } \\
\hat{\gamma}\end{array}$ & $\mathrm{SE}$ & $\mathrm{R}^{2}$ & \# obs. \\
\hline \multicolumn{7}{|c|}{ Wolters: $1984: 1-2002.4$} \\
\hline 2 & $\begin{array}{l}0.001 \\
(0.94)\end{array}$ & $\begin{array}{c}0.094 \\
(0.98)\end{array}$ & $\begin{array}{c}0.730 \\
(9.47)\end{array}$ & 0.0027 & 0.627 & 63 \\
\hline 4 & $\begin{array}{l}0.002 \\
(0.52)\end{array}$ & $\begin{array}{l}0.207 \\
(1.61)\end{array}$ & $\begin{array}{c}0.641 \\
(9.12)\end{array}$ & 0.0048 & 0.637 & 63 \\
\hline 9 & $\begin{array}{l}0.011 \\
(0.81)\end{array}$ & $\begin{array}{c}0.252 \\
(0.99)\end{array}$ & $\begin{array}{c}0.443 \\
(5.56)\end{array}$ & 0.0121 & 0.431 & 63 \\
\hline \multicolumn{7}{|c|}{ KRS: 1994:1-2008:4 } \\
\hline 2 & $\begin{array}{l}0.005 \\
(2.74)\end{array}$ & $\begin{array}{l}-0.522 \\
(-2.70)\end{array}$ & $\begin{array}{c}1.063 \\
(4.88)\end{array}$ & 0.0027 & 0.421 & 56 \\
\hline 5 & $\begin{array}{l}0.017 \\
(5.23)\end{array}$ & $\begin{array}{l}-0.620 \\
(-2.53)\end{array}$ & $\begin{array}{c}0.972 \\
(3.57)\end{array}$ & 0.0055 & 0.462 & 56 \\
\hline \multicolumn{7}{|c|}{ EG: 1992:1-2010:1 } \\
\hline 2 & $\begin{array}{l}0.003 \\
(1.49)\end{array}$ & $\begin{array}{l}-0.320 \\
(-3.67)\end{array}$ & $\begin{array}{c}1.000 \\
(4.85)\end{array}$ & 0.0030 & 0.405 & 71 \\
\hline 4 & $\begin{array}{l}0.008 \\
(2.11)\end{array}$ & $\begin{array}{l}-0.365 \\
(-1.94)\end{array}$ & $\begin{array}{c}0.926 \\
(3.55)\end{array}$ & 0.0055 & 0.359 & 70 \\
\hline 8 & $\begin{array}{l}0.032 \\
(3.56)\end{array}$ & $\begin{array}{l}-0.514 \\
(-1.56)\end{array}$ & $\begin{array}{c}0.723 \\
(2.25)\end{array}$ & 0.0098 & 0.234 & 66 \\
\hline \multicolumn{7}{|c|}{ NYFRB: 1992:1-2016:1 } \\
\hline 2 & $\begin{array}{l}0.004 \\
(2.81)\end{array}$ & $\begin{array}{l}-0.007 \\
(-0.11)\end{array}$ & $\begin{array}{l}0.613 \\
(5.11)\end{array}$ & 0.0031 & 0.308 & 97 \\
\hline 4 & $\begin{array}{l}0.008 \\
(3.58)\end{array}$ & $\begin{array}{l}0.009 \\
(0.11)\end{array}$ & $\begin{array}{l}0.546 \\
(3.96)\end{array}$ & 0.0053 & 0.311 & 97 \\
\hline 8 & $\begin{array}{l}0.024 \\
(3.76)\end{array}$ & $\begin{array}{l}-0.021 \\
(-0.14)\end{array}$ & $\begin{array}{l}0.373 \\
(2.07)\end{array}$ & 0.0101 & 0.172 & 97 \\
\hline 12 & $\begin{array}{l}0.047 \\
(2.98)\end{array}$ & $\begin{array}{l}-0.087 \\
(-0.39)\end{array}$ & $\begin{array}{l}0.240 \\
(2.47)\end{array}$ & 0.0141 & 0.087 & 93 \\
\hline
\end{tabular}

$P$ is the $\log$ of the GDP deflator.

OLS estimates.

$\mathrm{t}$-statistics are in parentheses. 12

Estimated standard errors are corrected for heteroscedasticity and a moving average process (except for Wolters). 
The results for NYFRB for consumption, investment, and OTHER are in Table 3, which has the same format as Tables 1 and 2. The results in Table 3 are less systematic across forecast horizons than are those in Tables 1 and 2. For consumption the DSGE estimates of $\beta$ are significant or close to being significant across the four horizons. The estimates of $\gamma$ are significant for horizons of 2 and 4 quarters. The results thus say that both forecasts contain independent information for horizons 2 and 4 quarters, but for horizons 8 and 12 quarters the CSAR4 forecasts contain no information not in the DSGE forecasts and the DSGE forecasts contain additional information.

For horizons of 2 and 4 quarters for both investment and OTHER the estimates of $\beta$ are not significant and the estimates of $\gamma$ are. The DSGE forecasts thus do not contain information not in the ISAR4 and OSAR4 forecasts, and the latter contain information not in the former. For horizons of 8 and 12 quarters the R squares are quite low. The estimate of $\beta$ is significant for investment and horizon 12 and for OTHER for horizon 8 , but it is hard to know what to make of this. Very little is explained for horizons 8 and 12 by either forecast. 
Table 3

Estimates of Equation (1) for Consumption, Investment, and OTHER

Forecasts are NYFRB Forecasts

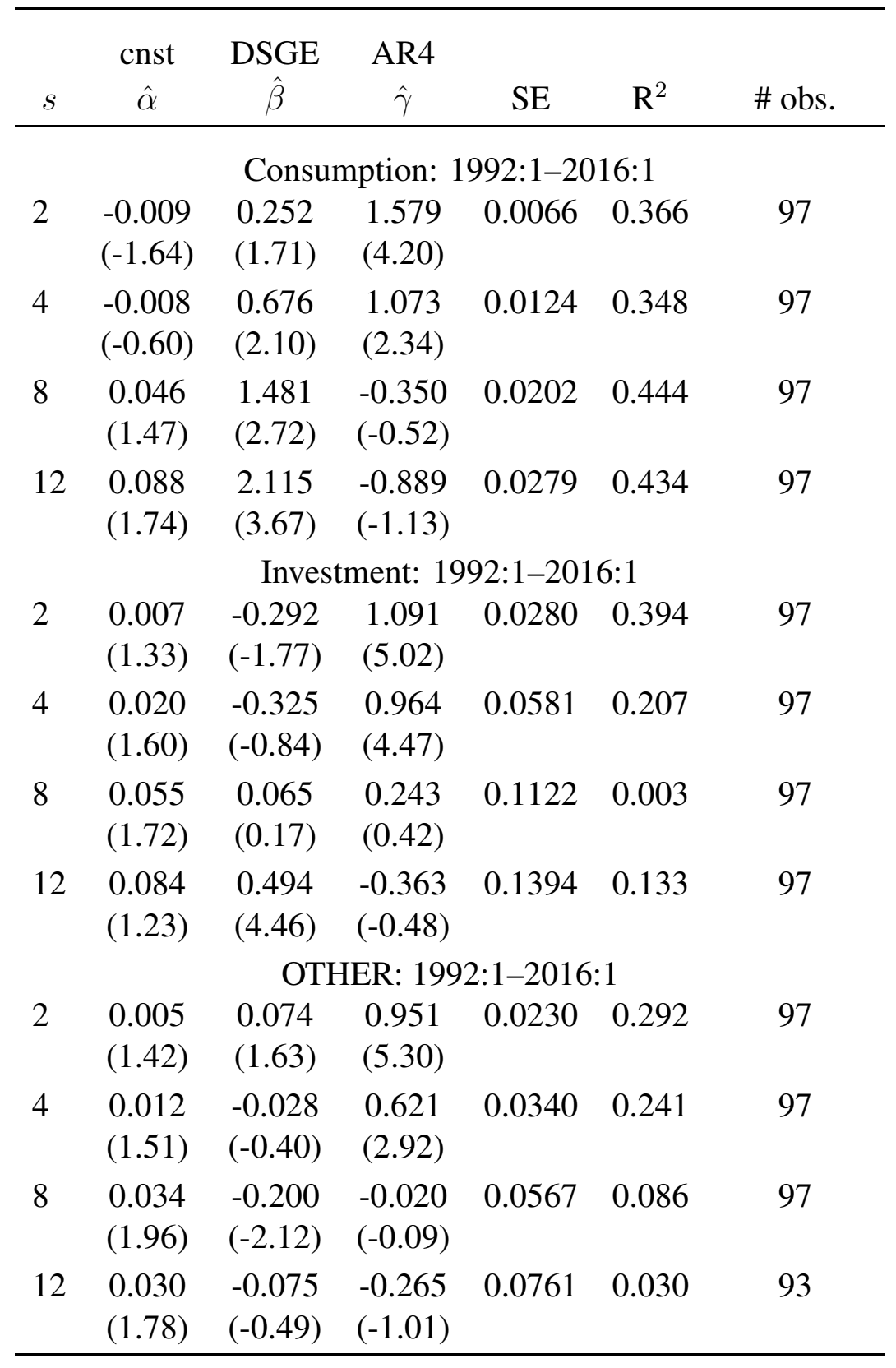

Left hand side variable is $X_{t}-X_{t-s} P$, where $X$ is the $\log$ of consumption, investment, or OTHER.

AR4 is CSAR4, ISAR4, or OSAR4-see text.

OLS estimates; $t$-statistics are in parentheses.

Estimated standard errors are corrected for heteroscedasticity and a moving average process. 


\section{Conclusion}

The results in Table 1 are quite strong for the DSGE forecasts of real GDP. The forecasts seem to contain all the information in the lagged values, at least as reflected in the YSAR4 forecasts, plus more. This is also true for consumption in Table 3 for horizons 8 and 12. For horizons 2 and 4 there is information in the CSAR4 forecasts not in the DSGE forecasts. For investment and OTHER in Table 3 the results are weaker, where if one ignores horizons of 8 and 12 quarters (where very little is explained) there is no independent information in the DSGE forecasts. The DSGE results are poor for the GDP deflator in Table 2, especially for Wolters and NYFRB, where the DSGE forecasts contain no independent information.

It should be stressed that the comparisons here are only with respect to forecasts from a model with only lagged values as explanatory variables. There are clearly other forecasts that could be used. A key difficulty in this area is abiding by the rules in Section 2, in particular avoiding the use of future information in generating the forecasts. Cai et al. (2018) contains an extensive comparison of the NYFRB forecasts with those of others, although their analysis is not structured to examine the independent information question in this paper.

In previous writings I have been critical of the DSGE methodology and the use of data-see, for example, Fair (2012). From the perspective of a one who works with large scale macroeconometric models, there is a lack of care in dealing with the data. It was mentioned above that real consumption and investment are mismeasured. Also, some of the labor force and population variables have not been handled correctly. And there is too much aggregation of the data. The behavior 
of service, nondurable, and durable consumption is quite different in the macro economy, and much is likely to be lost in aggregating the three. Also, plant and equipment investment and housing investment behave much differently, and these should not be aggregated. Ignoring imports is also problematic, since the United States is far from being a closed economy and import demand is endogenous. On the theory side, the theoretical restrictions are very tight, especially the imposition of rational expectations and the tight use of the maximization framework.

For a critic of DSGE models the results in Table 1 for real GDP may thus be surprising. As noted in the Introduction, lagged values are used extensively in DSGE models (sometimes in ad hoc ways!), and one might have thought that the use of the lagged values is driving the forecast results. The results in Table 1 show that this is not the case. The use of the FS comparison method shows that there is information in the DSGE forecasts for real output not in the lagged values. The puzzle to a critic is why the tight theoretical restrictions improve the forecasts.

The main question about the present results is whether future information is being used in forecasting real GDP. For example, some of the parameters in DSGE models are calibrated and fixed for all the forecasts. Is future information used in some of the calibrations? For the NYFRB forecasts, is the use of the Blue Chip expectations in the zero lower bound period cheating in some way regarding the information in the model qua model? Finally, has information on the financial crisis led to specification changes in DSGE models that help forecast the crisis period even when the rules in Section 2 are followed? 


\section{References}

[1] Cai, Michael, Marco Del Negro, Marc P. Giannoni, Abhi Gupta, Pearl Li, and erica Moszkowski, 2018, "DSGE Forecasts of the Lost Recovery," Federal Reserve Bank of New York Staff Report No. 844, March.

[2] Cumby, Robert E., John, Huizinga, and Maurice Obstfeld, 1983, “Two-Step Two Stage Least Squares in Models with Rational Expectations," Journal of Econometrics, 21, 333-355.

[3] Edge, Rochelle M., and Refet S. Gürkaynak, 2010, "How Useful are Estimated DSGE Model Forecasts for Central Bankers?" Brookings Papers on Economic Activity, Fall, 209-259.

[4] Fair, Ray c., 2012, "Has Macro Progressed?" Journal of Macroeconomics, $2-10$.

[5] Fair, Ray C., and Robert J. Shiller, 1990, "Comparing Information in Forecasts from Econometric Models," The American Economic Review, 375389.

[6] Hansen, Lars Peter, 1982, "Large Sample Properties of Generalized Method of Moments Estimators," Economefrica, 50, 1029-1054.

[7] Kolasa, Marcin, Michal Rubaszek, and Pawel Skrzypczyński, 2012, "Putting the New Keynesian DSGE Model to a Real-Time Forecasting Test," Journal of Money, Credit, and Banking, 44, 1301-1324.

[8] Smets, Frank, and Rafael Wouters, 2007, "Shocks and Frictions in US Business Cycles: A Bayesian DSGE Approach," The American Economic Review, 97, 586-606.

[9] White, Halbert, 1980, "A Heteroskedasticity Consistent Covariance Matrix Estimator and a Direct Test for Heteroskedasticity," Econometrica, 48, 817838.

[10] White, Halbert, and Ian Domowitz, 1984, "Nonlinear Regression with Dependent Observations," Econometrica, 52, 143-161.

[11] Wolters, Maik H., 2013, "Evaluating Point and Density Forecasts of DSGE Models," Journal of Applied Econometrics, 30, 74-96. 